\title{
EFEITOS DO DECANOATO DE NANDROLONA NA FUNÇÃO SEXUAL DE RATOS WISTAR
}

\author{
Franciele Januário de Lima ${ }^{*}$, Letícia Cristina Vellozo Correia ${ }^{1}$, Beatriz Baldo de \\ Almeida ${ }^{1}$, Loreane Aparecida Spirlandelli da Costa ${ }^{1} \&$ Ana Rosa Crisci ${ }^{1}$
}

LIMA, F.J.; CORREIA, L.C.V; ALMEIDA, B.B.; COSTA, L.A.S. \& CRISCI, A.R. Efeitos do decanoato de nandrolona na função sexual de ratos wistar. Perspectivas Online: Biológicas \& Saúde. v. 8, n 27, p.18-26, 2018.

\section{RESUMO}

Os esteroides anabólicos androgênicos (EAA) são derivados sintéticos da testosterona que há muito tempo vem sendo discutidos na área científica. $\mathrm{O}$ consumo sem fins terapêuticos vem expandindo em meio à população jovem, que faz o uso inconsciente de superdoses, com a finalidade de aprimorar o desempenho atlético, gerando assim um problema de saúde pública. Deste modo, é imprescindível aprofundar os estudos que visam avaliar os possíveis efeitos colaterais relacionados a esse consumo. O objetivo desse estudo foi investigar os efeitos causados na morfologia testicular, nos níveis de testosterona e nos parâmetros seminais de ratos da linhagem Wistar, após a administração de Decanoato de Nandrolona na concentração de $5 \mathrm{mg} / \mathrm{kg}$. Os animais $(\mathrm{n}=20)$ foram divididos em dois grupos: tratamento $(5 \mathrm{mg} / \mathrm{kg}$ de Decanoato de Nandrolona) e controle (5 mg/kg de Óleo de Amendoim), nos quais foram administrados por via intramuscular duas vezes por semana, durante oito semanas consecutivas. Os resultados demonstraram diminuição significativa nos níveis de testosterona, alguns tipos de anomalias na morfologia dos espermatozoides, alterações nas células da linhagem espermatogênica dos túbulos seminíferos e o aumento de vacúolos no espaço intertubular dos testículos. Concluiu-se que o uso desse esteroide, na dose $5 \mathrm{mg} / \mathrm{kg}$, apresenta um efeito prejudicial ao sistema reprodutor masculino.

Palavras-chave: Decanoato de Nandrolona; Testículos; Testosterona; Esteroide anabólico androgênico. 


\begin{abstract}
Anabolic androgenic steroids (AAS) are synthetic derivatives of testosterone that have long been discussed in the scientific field. Non-therapeutic use has been expanding among young people, in which uses unconscious overdoses, to improve athletic performance, thus generating a public health problem. Therefore, it is indispensable to analyze the possible side effects related to this consumption. The objective of this study was to investigate the possible effects on testicular morphology, on testosterone levels and on the seminal parameters of Wistar rats after administration of Nandrolone Decanoate at a

were divided in two groups: treatment $(5 \mathrm{mg} / \mathrm{kg}$ of Nandrolone Decanoate) and control $(5 \mathrm{mg} / \mathrm{kg}$ of peanut oil), in which they were given intramuscularly twice a week, during eight consecutive weeks. The results demonstrated a significant decrease in testosterone levels, some types of anomalies in sperm morphology, alterations in the spermatogenic cells of the seminiferous tubes and increase of vacuoles in the intertubular space of the testis. It was concluded that the use of this steroid, at a dose of $5 \mathrm{mg} / \mathrm{kg}$, has a harmful effect on the male reproductive system.
\end{abstract} concentration of $5 \mathrm{mg} / \mathrm{kg}$. The animals $(\mathrm{n}=20)$

Keywords: Nandrolone Decanoate; Testis; Testosterone; Anabolic androgenic steroids.

1 Centro Universitário Barão de Mauá - CBM - R. Ramos de Azevedo, 423 - Jardim Paulista, Ribeirão Preto - SP, CEP: 14090-180 - Brasil.

(*)e-mail: franciellejlima@ hotmail.com

Data de chegada: 18/05/2018 Aceito para publicação: 14/05/2018 


\section{INTRODUÇÃO}

Os esteroides anabólicos androgênicos (EAA) são derivados sintéticos da testosterona que foram desenvolvidos com o objetivo de minimizar seus efeitos androgênicos e potencializar suas propriedades anabólicas. A sua ação androgênica é responsável pelo desenvolvimento e manutenção das características sexuais masculinas, enquanto que sua propriedade anabólica aumenta a síntese de proteínas nos tecidos e músculos (PEDROSO, 2014).

Estes esteroides sintéticos, conhecidos popularmente por anabolizantes, estão divididos em dois grupos: derivados esterificados (fenilpropionato de nandrolona, decanoato de nandrolona, enantato de testosterona e cipionato de testosterona), nos quais são administrados por via intramuscular, e derivados alcalinizados (oximetolona, metandrostenolona e estanozolol), que são utilizados por via oral (SNYDER, 2012).

O Decanoato de Nandrolona se configura como um dos EAA mais procurados no mundo (KUTSCHER; LUND; PERRY, 2002). Comparativamente à testosterona, apresenta uma alto potencial anabólico e uma menor atividade androgênica (WILSON; GRIFFIN; RUSSELL, 1993). Além disso, é um dos mais citados na literatura, devido ao seu perfil tóxico, com ação no sistema reprodutor masculino, agindo principalmente nos níveis de testosterona, morfologia dos testículos e dos espermatozoides (MIN; LEE, 2018; NOORAFSHAN; KARBALAY-DOUST; ARDEKANI, 2005).

No sistema reprodutor masculino, o consumo de EAA inibe a produção de hormônio luteinizante (LH) e hormônio folículo estimulante (FSH) por meio do mecanismo de retroalimentação negativa, levando a redução nos níveis de testosterona endógena (TAKAHASHI; TATSUGI; KOHNO, 2004). Este distúrbio hormonal promove ginecomastia, atrofia testicular, ejaculação precoce, oligozoospermia e alterações na morfologia dos espermatozoides (KALININE, 2011; DECANINE et al., 2010). A maioria destes efeitos é reversível, porém, o uso prolongado de esteroides resulta em quadros clínicos mais severos, tais como, azoospermia, hipertrofia prostática e carcinoma prostático (PEDROSO, 2014).

Apesar de serem substâncias ilícitas para fins não terapêuticos, atualmente a incidência do consumo de EAA tem aumentado consideravelmente e seu uso está predominantemente associado a atletas profissionais e amadores (LIMA; CARDOSO, 2011). Devido a este fato, é imprescindível aprofundar os estudos que visam avaliar os possíveis efeitos colaterais relacionados ao seu consumo.

Portanto, o objetivo desse estudo foi investigar os efeitos causados na morfologia testicular, nos níveis de testosterona e nos parâmetros seminais de ratos da linhagem Wistar, após a administração de Decanoato de Nandrolona na concentração de $5 \mathrm{mg} / \mathrm{kg}$.

\section{METODOLOGIA}

O presente trabalho trata-se de uma pesquisa de natureza básica, com procedimento exploratório, experimental e de abordagem quantitativa. A pesquisa foi submetida à análise e aprovada pelo Comitê de Ética em Pesquisa e Experimentação Animal (CEPan), do Centro Universitário Barão de Mauá, conforme o protocolo $n^{\circ} 282 / 17$.

Foram utilizados 20 ratos machos da linhagem Wistar, com idade aproximada de 60 dias e peso corpóreo inicial de 200 gramas. De acordo com Neves et al. (2013) e Santos (2002), os animais do presente estudo apresentavam idade reprodutiva e teriam atingido maturação sexual para iniciar o tratamento experimental.

Os ratos foram alojados em gaiolas individuais de polipropileno contendo cama de maravalha, grade superior e mantidos em ambiente controlado, com temperatura de 21 a $24^{\circ} \mathrm{C}$, recebendo água e ração própria suficiente para suprir a demanda energética durante todo o período experimental. 
O estudo teve duração de 56 dias e os animais foram divididos em 2 grupos, contendo 10 ratos cada: grupo de tratamento ( $5 \mathrm{mg} / \mathrm{kg}$ de Decanoato de Nandrolona diluído em $0,4 \mathrm{~mL}$ de óleo de amendoim) e grupo controle $(5 \mathrm{mg} / \mathrm{kg}$ de óleo de amendoim). As aplicações foram realizadas por via intramuscular, 2 vezes na semana, sempre às segundas e quintas-feiras, entre às $11 \mathrm{~h} 00$ e $11 \mathrm{~h} 30$. Antes de cada aplicação, os animais foram pesados para determinar o volume que seria administrado em ambos os grupos experimentais, considerando-se a dose de $5 \mathrm{mg} / \mathrm{kg}$.

A escolha de $5 \mathrm{mg} / \mathrm{kg}$ de Decanoato de Nandrolona, foi baseada nos estudos de Cardoso (2008) e Vieira et al. (2008), sendo considerada dose intermediária (VIEIRA et al., 2008). Segundo Norton, Trifunovic e Woodiwiss (2000), essa dose é equivalente às que normalmente são utilizadas em academias de ginástica.

No final do experimento, os animais foram eutanasiados com dose letal dos anestésicos cloridrato de ketamina $(100 \mathrm{mg} / \mathrm{kg})$, cloridrato de xilazina $(6 \mathrm{mg} / \mathrm{kg})$ e tiopenthal sódico $(40 \mathrm{mg} / \mathrm{kg})$.

Após o sacrifício foi coletado $10 \mathrm{~mL}$ de sangue pelo método de punção cardíaca para dosagem de testosterona total, através do método de quimioluminescência. Segundo Chaves (2005), é importante que as análises tenham um planejamento estatístico para maior confirmação das hipóteses, portanto, todas as dosagens desta pesquisa foram realizadas em triplicatas e analisadas por mais de um pesquisador.

Foi realizada uma laparotomia exploratória para retirada dos testículos e epidídimos, para avaliações histopatológicas e coleta do sêmen, respectivamente. Os testículos foram pesados em balança analítica GEHAKA BG-2000® e depois fixados em formaldeído a 10\% no tempo mínimo de 48 horas, em seguida foram submetidos ao processo de desidratação em uma série crescente de álcoois etílicos $(70 \%, 80 \%, 90 \%$ e absoluto), posteriormente procedeu-se a diafanização do material em xilol (I, II e III) e impregnação em parafina à $60^{\circ} \mathrm{C}$ por 2 horas para consecutivo emblocamento. Após estas etapas, os fragmentos foram submetidos ao corte em micrótomo rotativo de 6 micras, onde foram fixados e corados pelo método de Hematoxilina-eosina (HE). Subsequentemente foram desparafinizados em xilol, hidratados em álcoois decrescentes (absoluto, 90\%, 80\% e 70\%) e destinados a montagem com lamínula. Após o processamento do material, as lâminas foram analisadas no microscópio Nikon Eclipse E100 ${ }^{\circledR}$ e as fotomicrografias obtidas em fotomicroscópio HD Lite $1080 \mathrm{P}^{\circledR}$.

O sêmen foi coletado por perfuração da cauda do epidídimo, em seguida foi diluído em $1 \mathrm{~mL}$ de solução fisiológica e incubado à $37^{\circ} \mathrm{C}$. Realizou-se a análise microscópica do vigor, observando um total aproximado de 200 espermatozoides, com aumento 40X. A motilidade foi avaliada qualitativamente pela classificação de zero (imóvel) a 5 (motilidade rápida). Para análise morfológica, o esfregaço preparado foi corado com Eosina-Nigrosina e a morfologia foi observada em microscopia, com aumento 100X, onde foram analisados 100 espermatozoides, especificando as anomalias encontradas.

Nos parâmetros seminais e dosagem da testosterona, foram calculados a média e o erro-padrão e para comparação entre os grupos experimentais, utilizou-se o teste paramétrico t-Student bilateral não-pareado, onde o nível de significância adotado foi $\mathrm{p} \leq 0,05$.

\section{RESULTADOS E DISCUSSÃO}

\subsection{Histopatologia dos testículos}

Nas secções testiculares do grupo tratado, os túbulos seminíferos apresentaram em muitas áreas, alterações na citoarquitetura do epitélio, com descamação de células germinativas para o lúmen tubular (Figura 1B e 1D). Além disso, observou-se aumento no espaço intertubular com a presença de vacúolos (Figura 1D).

No grupo controle (Figura 1A e 1C), os túbulos seminíferos apresentaram epitélio íntegro e células da linhagem espermatogênica em todas as etapas de desenvolvimento. Não foi observada alteração no espaço intertubular, no qual, apresentou vasos sanguíneos e células de Leydig, com núcleo excêntrico e esférico. 
A descamação das células espermatogênicas para a luz dos túbulos seminíferos, também foi observada nos grupos tratados com Decanoato de Nandrolona nos experimentos de Decanine et al. (2010) e Takahashi, Tatsugi e Kohno (2004). Além dessa alteração, Barone et al. (2017), relatou também modificações degenerativas e desorganização em alguns túbulos seminíferos com maturação incompleta das células, semelhante às áreas que apresentaram alteração nas células germinativas do presente estudo. A partir desses achados na literatura e sob as condições em que o experimento foi desenvolvido, é possível observar que o Decanoato de Nandrolona afeta a estrutura tubular seminífera. Sugere-se que estas alterações são decorrentes dos efeitos negativos do esteroide no eixo neuroendócrino masculino, no qual altera os níveis de FSH e LH.

A atrofia e a redução de células de Leydig, é um resultado frequente quando está associado ao uso de Decanoato de Nandrolona (MIN; LEE, 2018; BARONE et al., 2017; TAKAHASHI; TATSUGI; KOHNO, 2004) porém este efeito não foi encontrada no presente estudo.
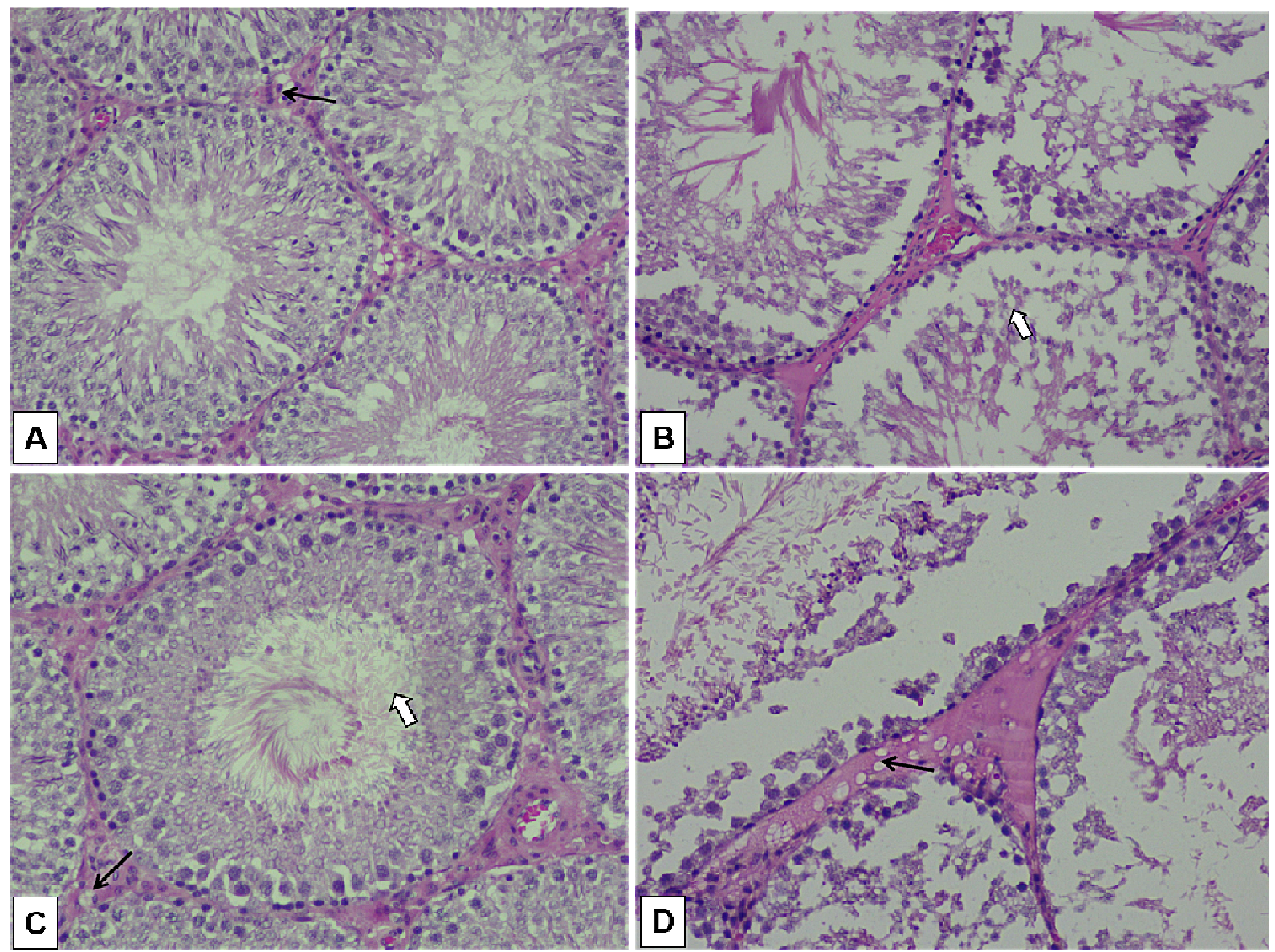

Figura 1- Fotomicrografias dos testículos dos grupos experimentais. Fig. A e C: secções testiculares do grupo controle, apresentando espaço intertubular contendo vasos sanguíneos e células de Leydig (setas pretas). Células espermatogênicas em todas as etapas de desenvolvimento (seta branca). Fig. B e D: secções testiculares do grupo tratado, apresentando descamação das células germinativas para o lúmen tubular (seta branca). Espaço intertubular aumentado e com vacúolos (seta preta). Aumento 100X (A, B) e 400X (C, D).

\subsection{Testosterona Total}

A dosagem da testosterona total no grupo tratado com o Decanoato de Nandrolona diminuiu significativamente $(p=0,001)$, concordando com o estudos de Min e Lee (2018), Barone et al. (2017) e Decanine et al. (2010) (Figura 2), nos quais, os grupos esteroidais apresentaram uma drástica diminuição deste hormônio. 
Barone et al. (2017), sugeriram que o uso de Decanoato de Nandrolona, causa uma supressão nos níveis de LH e FSH, e consequentemente ocorre a redução na síntese e liberação de testosterona endógena, sendo que, o LH é responsável por estimular a produção da testosterona nas células de Leydig. Portanto, isso explica a diminuição dos níveis séricos no grupo de tratamento.

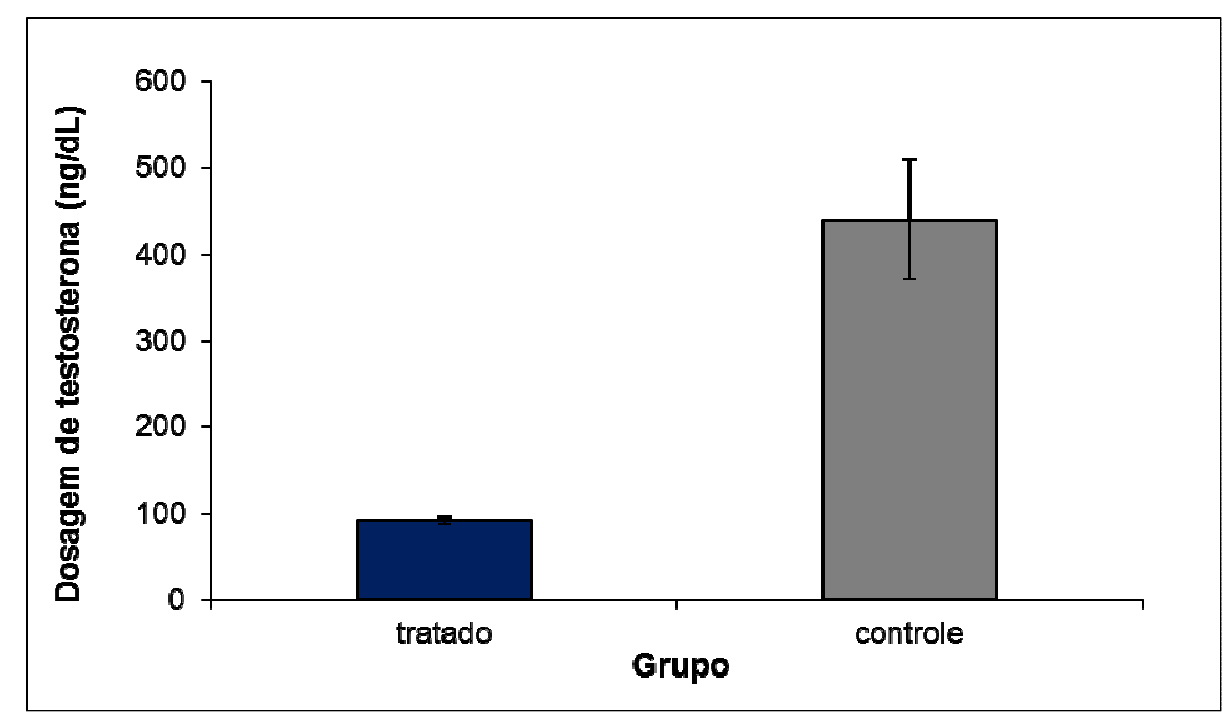

Figura 2 - Média dos níveis séricos de testosterona total

\subsection{Espermograma}

O vigor dos espermatozoides de todos os animais, receberam classificação 5 (motilidade rápida), desta forma não houve diferença significativa entre os grupos experimentais. Estes resultados concordam com o estudo de Cardoso (2008), que também não observou neste parâmetro, efeitos negativos decorrentes do uso de Decanoato de Nandrolona.

Observou-se uma variedade de alterações na morfologia dos espermatozoides do grupo tratado (Figura 3C-F), onde as anomalias de cauda em angulação acentuada e acefálico apresentaram diferença estatística significativa entre os grupos experimentais $(\mathrm{p}=0,002)$ e $(\mathrm{p}=0,0002)$, respectivamente. A análise morfológica dos espematozoides dos grupos experimentais é apresentada na Tabela 1.

Shokri et al. (2014) demonstraram em seu estudo, que a morfologia normal dos espermatozoides do grupo esteroide, apresentou percentual significativamente baixo em relação aos grupos que não receberam a droga. Porém, nos resultados encontrados por Cardoso (2008), a morfologia dos espermatozoides, não apresentou diferença significativa entre os grupos.

Segundo Bonetti et al. (2008), a redução nos níveis de FSH pode levar a diminuição da contagem, mobilidade e modificações na morfologia dos espermatozoides. Relacionando com os achados do presente estudo, esta afirmação, associada à diminuição da testosterona, pode ser uma hipótese da origem das anomalias nos espermatozoides, já que os dois hormônios atuam durante a espermatogênese.

Desta forma, a partir desses resultados, não é possível afirmar que o Decanoato de Nandrolona, na dose utilizada e sob as condições em que o presente experimento foi desenvolvido, pode levar à infertilidade, uma vez que, este quadro tem origem multifatorial (SANTOS et al., 2013) e seria necessário avaliar outros parâmetros reprodutivos. 

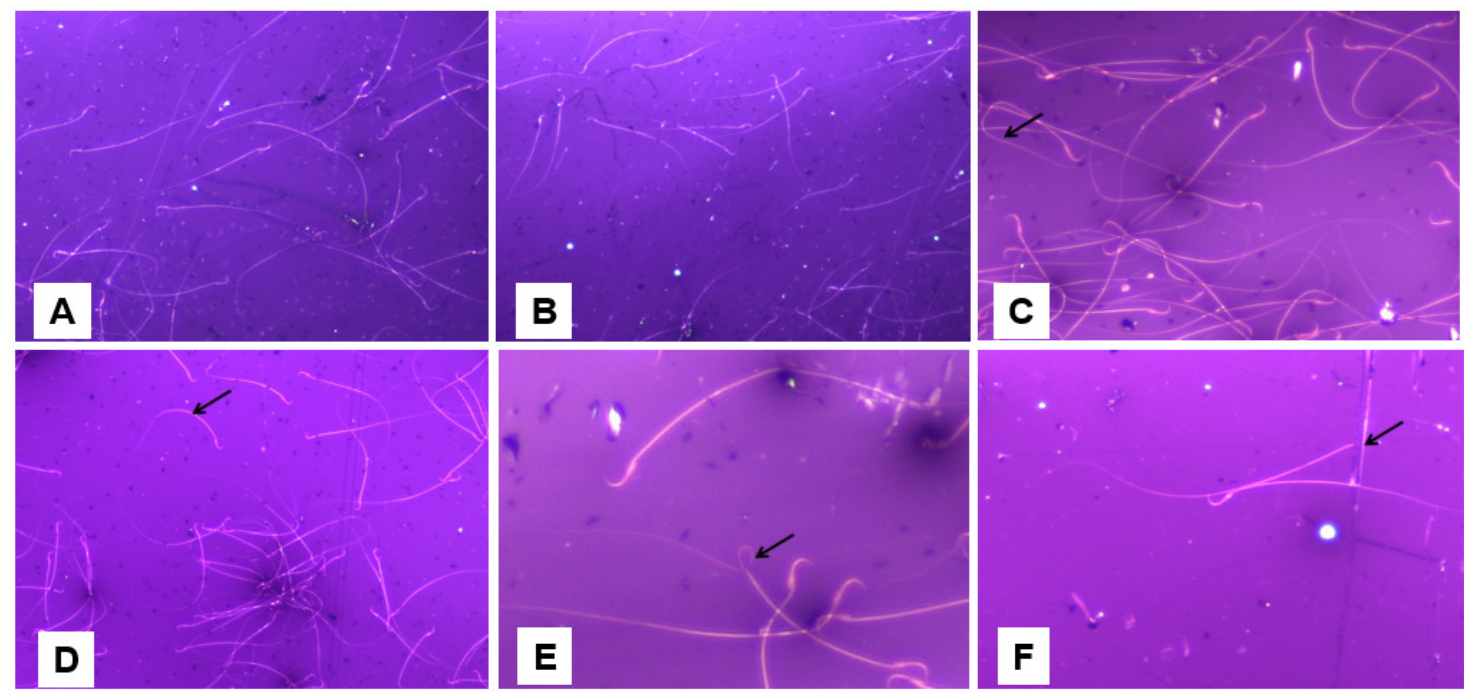

Figura 3 - Esfregaço dos espermatozoides. Em A e B: espermatozoides do grupo controle, com morfologia normal. Em

C, D, E e F, espermatozoides do grupo tratado, C: cauda com angulação acentuada (seta), D: cauda com angulação atenuada (seta), E: cauda enrolada (seta), F: acéfalo (seta). Aumento 100X. Coloração Eosina-Nigrosina.

Tabela 1- Média e erro-padrão da morfologia dos espermatozoides dos grupos experimentais

\begin{tabular}{|c|c|c|c|c|c|c|c|c|}
\hline & \multirow{2}{*}{$\begin{array}{c}\text { Morfologia } \\
\text { normal } \\
\%\end{array}$} & \multirow{2}{*}{$\begin{array}{c}\text { Anomalias } \\
\text { de cabeça } \\
\% \\
\text { ACF } \\
\end{array}$} & \multicolumn{4}{|c|}{ Anomalias de cauda $\%$} & \multirow{2}{*}{$\begin{array}{c}\text { Anomalias } \\
\text { de gancho } \\
\% \\
\text { SG } \\
\end{array}$} & \multirow{2}{*}{$\begin{array}{c}\underset{\%}{\text { Anomalias }} \text { múltiplas } \\
\% \\
\text { SG+SC } \\
\end{array}$} \\
\hline & & & SC & $\mathbf{C E}$ & CAT & CAA & & \\
\hline $\begin{array}{c}\text { Grupo } \\
\text { Controle }\end{array}$ & $89,22 \pm 0,55$ & $1,56 \pm 0,38$ & $6,89 \pm 0,59$ & $0,33 \pm 0,17$ & $0,22 \pm 0,15$ & $0,56 \pm 0,34$ & $0,33 \pm 0,17$ & $0,56 \pm 0,24$ \\
\hline $\begin{array}{c}\text { Grupo } \\
\text { Tratado }\end{array}$ & $76,40 \pm 2,28$ & $4,10 \pm 0,41^{*}$ & $8,20 \pm 0,93$ & $1,30 \pm 0,52$ & $0,50 \pm 0,34$ & $7,50 \pm 1,67 *$ & $0,30 \pm 0,21$ & $0,60 \pm 0,31$ \\
\hline
\end{tabular}

ACF: acéfalo (sem cabeça), SC: sem cauda, CE: cauda enrolada CAT: cauda com angulação atenuada, CAA: cauda com angulação acentuada, SG: sem gancho, SG + SC: sem gancho + sem cauda. $* \mathrm{P}<0,05$ na comparação entre o grupo tratado e o controle.

\subsection{Massa dos testículos}

O peso absoluto dos testículos não demonstrou diferença estatística significativa entre os grupos experimentais (Figura 4), concordando com o estudo de Cardoso (2008). Entretanto, há uma contradição com os experimentos de Kalinine (2011) e Noorafshan, Karbalay-doust e Ardekani (2005), pois o tratamento com o Decanoato de Nandrolona causou a diminuição na massa dos testículos, em relação aos animais não tratados. Uma hipótese pode ser a de que a dose usada, a quantidade de aplicações e o período experimental do presente estudo, não leva à estas alterações. Talvez um tratamento suprafisiológico, como no estudo de Kalinine, teria resultado na atrofia testicular. 


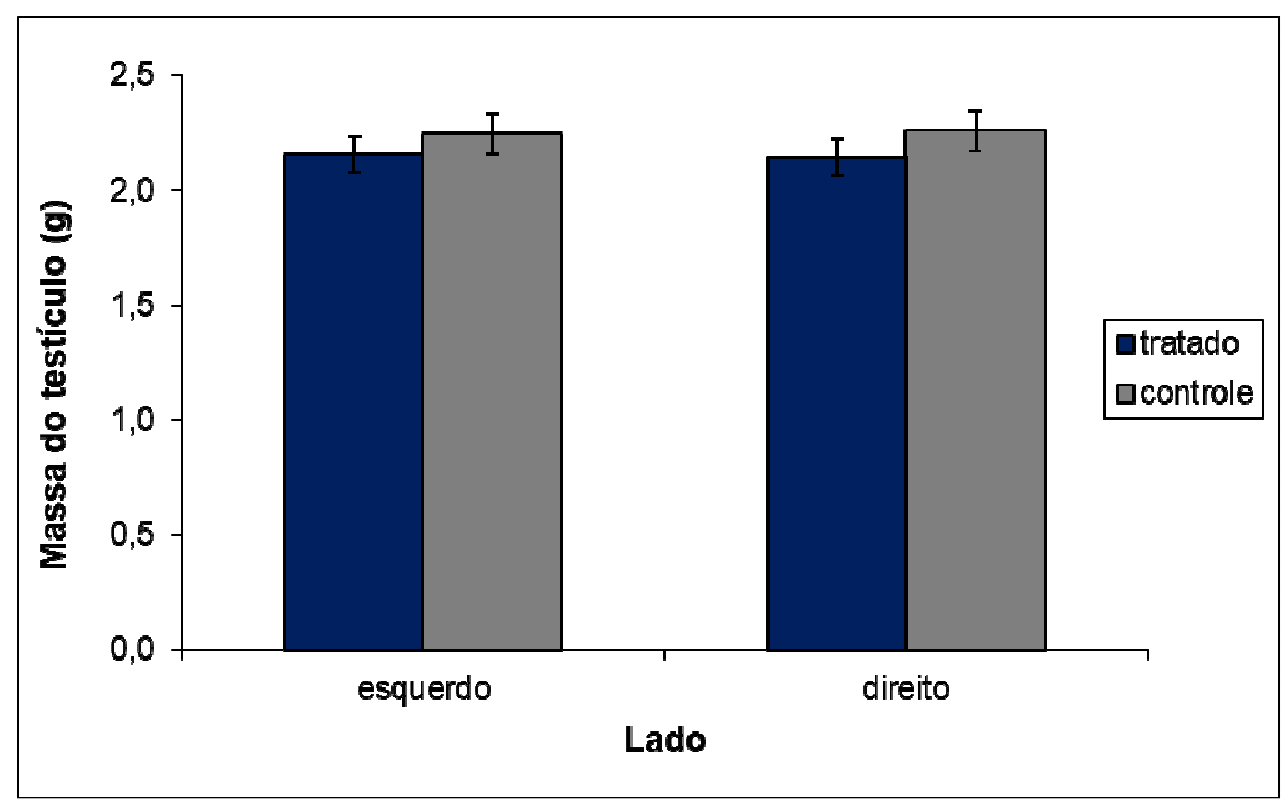

Figura 4 - Massa média dos testículos

\section{CONCLUSÕES}

De acordo com os dados obtidos, foi possível observar que a administração do Decanoato de Nandrolona na dose $5 \mathrm{mg} / \mathrm{kg}$ e nas condições em que a pesquisa foi realizada, causa alguns tipos de anomalias na morfologia dos espermatozoides, provoca alterações nos túbulos seminíferos e no espaço intertubular dos testículos. Além disso, é responsável também pela diminuição significativa nos níveis de testosterona. No entanto, o uso do esteróide não interferiu na motilidade dos espermatozóides e na massa dos testículos.

Portanto, pode ser considerado que existe um alto risco de efeitos prejudiciais no sistema reprodutor masculino, relacionado ao uso Decanoato de Nandrolona.

\section{REFERÊNCIAS}

BARONE, R. et al. Nandrolone decanoate interferes with testosterone biosynthesis altering blood-testis barrier components. Journal of Cellular and Molecular Medicine, v. 21, n. 8, p.1636-1647, 2017.

BONETTI, A. et al. Side effects of anabolic androgenic steroids abuse. International Journal of Sports Medicine, Nova Iorque, v. 29, n. 8, p.679-687, 2008.

CARDOSO, F. F. Aspectos reprodutivos e sociais e resistência óssea em ratos machos submetidos ao exercício físico e/ou a um anabolizante esteróide. 2008. 39 f. TCC (Graduação) - Curso de Ciências Biológicas, Universidade Estadual Paulista, Botucatu, 2008.

CHAVES, J. B. P. Planejamento Estatístico de Experimentos Científicos. 2005. Disponível em: <http://www.minaslac.dta.ufv.br/artigos/planestat.htm>. Acesso em: 03 abr. 2017.

DECANINE, C. et al. Análise da estrutura testicular e do comportamento sexual de ratos machos Wistar submetidos ao tratamento com esteroide anabólico androgênico, decanoato de nandrolona. In: ENCONTRO ANUAL DE INICIAÇÃO CIENTIFICA UNICENTRO, 19., 2010, Guarapuava - PR. Anais do XIX EAIC. Guarapuava - PR, 2010. p. 1 - 4.

KALININE, E. Efeitos comportamentais, neuroquímicos e metabólicos do tratamento com decanoato de nandrolona em camundongos. 2011. 63 f. Dissertação (Mestrado) - Curso de Bioquímica, Universidade Federal do Rio Grande do Sul, Porto Alegre, 2011.

KUTSCHER, E. C.; LUND, B. C.; PERRY, P. J. Anabolic Steroids Sports Medicine, Auckland, v. 32, n. 5 , p.285-296, 2002. 
LIMA, A. P. de; CARDOSO, F. B. Alterações fisiológicas e efeitos colaterais decorrentes da utilização de esteroides anabolizantes androgênicos. Revista Brasileira de Ciências da Saúde, João Pessoa, v. 29, n. 9 , p.39-46, set. 2011.

MIN, T; LEE, K.H. Effects of nandrolone decanoate on expression of steroidogenic enzymes in the rat testis. Asian-Australasian Journal of Animal Sciences, v. 31, n. 5, p.658-671, maio 2018.

NEVES, S. M. et al. Manual de Cuidados e Procedimentos com Animais de Laboratório do Biotério de Produção e Experimentação da FCF-IQ/USP. São Paulo: Fcf-iq/usp, 2013. 216 p.

NOORAFSHAN, A; KARBALAY-DOUST, S; ARDEKANI, F. High doses of nandrolone decanoate reduce volume of testis and length of seminiferous tubules in rats. Journal of Pathology Microbiology and Immunology, Shiraz, v. 113, n. 2, p.122-125, fev. 2005.

NORTON, G. R.; TRIFUNOVIC, B.; WOODIWISS, A. J. Attenuated beta-adrenoceptor-mediated cardiac contractile responses following androgenic steroid administration to sedentary rats. European Journal of Applied Physiology, v. 8, n.4, p.310-316, 2000.

PEDROSO, R. C. Esteróides Anabólicos Androgênicos. In: OGA, Seizi; CAMARGO, Márcia Maria de A.; BATISTUZZO, José Antonio de O. Fundamentos de Toxicologia. 4. ed. São Paulo: Atheneu, 2014. Cap. 62. p. 557-568.

SANTOS, B. F. Criação e manejo de ratos. In: ANDRADE, Antenor; PINTO, Sérgio Correia; OLIVEIRA, Rosilene Santos de. Animais de Laboratório: criação e experimentação. Rio de Janeiro: Fiocruz, 2002. p. $118-121$.

SANTOS, T. R. M. et al. Considerações sobre infertilidade masculina. Cadernos de Graduação - Ciências Biológicas e da Saúde, Aracaju, v. 1, n. 16, p.21-26, mar. 2013.

SHOKRI, S. et al. Nandrolone decanoate administration can increase apoptosis in spermatogenesis cell lines in male rats. Journal of Basic Research in Medical Sciences, v. 1, n. 3, p.21-31, 2014.

SNYDER, P. J. Androgênios. In: L.BRUNTON, Laurence; CHABNER, Bruce A.;

KNOLLMANN, Björn C. As Bases Farmacológicas da Terapeutica de Goodman \& Gilman. 12. ed. Porto Alegre: Amgh, 2012. Cap. 5. p. 1195-1207.

TAKAHASHI, M.; TATSUGI, Y.; KOHNO, T. Endocrinological and pathological effects of anabolicandrogenic steroids in male rats. Endocrine Journal, Tóquio, v. 51, n. 4, p.425-434, 2004.

VIEIRA, R. P. et al. Dose-Dependent Hepatic Response to Subchronic Administration of Nandrolone Decanoate. Medicine \& Science in Sports \& Exercise, v. 40, n. 5, p.842-847, 2008.

WILSON, J.D.; GRIFFIN, J.E.; RUSSELL, D.W. Steroid 5 alpha-reductase 2 deficiency. Endocrine Reviews, Bethesda, v.14, n.5, p.577-593, 1993. 